\title{
NUMERICAL SIMULATION OF LARGE FABRIC FILTER
}

\author{
Jan SEDLÁČEK, Petr KOVAŘíK
}

\begin{abstract}
Fabric filters are used in the wide range of industrial technologies for cleaning of incoming or exhaust gases. To achieve maximal efficiency of the discrete phase separation and long lifetime of the filter hoses, it is necessary to ensure uniform load on filter surface and to avoid impacts of heavy particles with high velocities to the filter hoses. The paper deals with numerical simulation of two phase flow field in a large fabric filter. The filter is composed of six chambers with approx. 1600 filter hoses in total. The model was simplified to one half of the filter, the filter hoses walls were substituted by porous zones. The model settings were based on experimental data, especially on the filter pressure drop. Unsteady simulations with different turbulence models were done. Flow field together with particles trajectories were analyzed. The results were compared with experimental observations.
\end{abstract}

\section{INTRODUCTION}

Fabric filters are used in the wide range of industrial technologies for cleaning of incoming or exhaust gases. A fabric filter unit consists of one or more chambers containing rows of fabric bags. The bags can be in the form of round, flat, or shaped tubes, or pleated cartridges. In most cases, the polluted gas with solid particles passes up along the bags surface and then almost perpendicularly through the fabric. Particles are captured on the upstream surface of the bags and/or dust layer and the cleaned gas is vented to the outside atmosphere. The filter is operated periodically, alternating between periods of filtering and short periods of cleaning. During cleaning, collected dust cake on the bags surface is removed and deposited in a hopper. Shakers, back flow and pulse jet cleaning are used to remove them.

Fabric filters are able to collect particles with diameters in range from submicron to several hundred microns at efficiencies generally in excess of 99 to 99.9 percent. The high efficiency is primarily achieved by the dust cake collected on the fabric surface. The cake is a porous barrier that captures particles as they pass through the cake.

The fabric filters are used when high-efficiency particle collection is required. Limitations are imposed by gas characteristics (temperature and corrosivity) and particle characteristics (primarily size and stickiness).

The main process variables are particles, gas and fabric properties; the most important design parameter is the gas-to-cloth ratio. The operating parameter is usually pressure drop across the filter system that can be simply measured. Typical values of filter system pressure drop range from about 900 to $5.000 \mathrm{~Pa}$. The pressure drop differs in dependency on dust layer thickness and the fabric state (new / used).

\footnotetext{
- Západočeská univerzita v Plzni, NTC, Univerzitní 8, 30614 Plzeň, phone +420 377634 707, email: sedlacek@ntc.zcu.cz
}

This is an Open Access article distributed under the terms of the Creative Commons Attribution License 2.0, which permits unrestricted use, distribution, and reproduction in any medium, provided the original work is properly cited. 
Together with the pressure drop also the overall mass flow rate, particles concentrations and amount of the collected dust are often monitored [1] [3].

The filters are usually designed on the base of known empirical formulae and manufacturer's knowledge. The method does not provide detailed gas flow and particles distribution. Problems with non uniform gas distribution, oscillating flow and damage of filter hoses by heavy particles occur in some cases in operation. Numerical CFD analyses supported by experimental measurement can be employed to analyze the reason of these problems.

Fabric filters, especially the large filters with several chambers are unique devices made according to the customer requirements and with respect to the local conditions. Experimental measurement on these filters is very limited with respect to the customer needs, i.e. continuous operation without impact to the technological processes. The filtering system pressure drop, gas mass flow rate, gas temperature and basic dust properties are the experimental data often only available.

\section{COMPUTATIONAL MODEL}

The paper deals with CFD numerical simulation of two phase flow in a chosen large fabric filter. The filter is composed of six chambers with approx. 1600 filter hoses in total and pulse jet cleaning system. The filter cleaning is continuous process with time period of seconds between sequential propulsion of single bags rows in one chamber. The flow in the filter is thereby partly disturbed by the cleaning process.

With respect to the filter size and number of filter bags, the computational model was simplified. The filter bags had to be substituted by a porous zone. The substitution was prepared and solved in several variants: one simple porous block in each chamber, porous jump on each bag wall, combination of porous jump and porous zone and finally, tubular porous zone of each filter bag wall. The final substitution (presented in this paper - see Figure 1) led to significant increase of computational elements number; therefore the geometry had to be simplified to one half of the filter size - see Figure1. The number of computational elements reached almost 25 millions anyway.
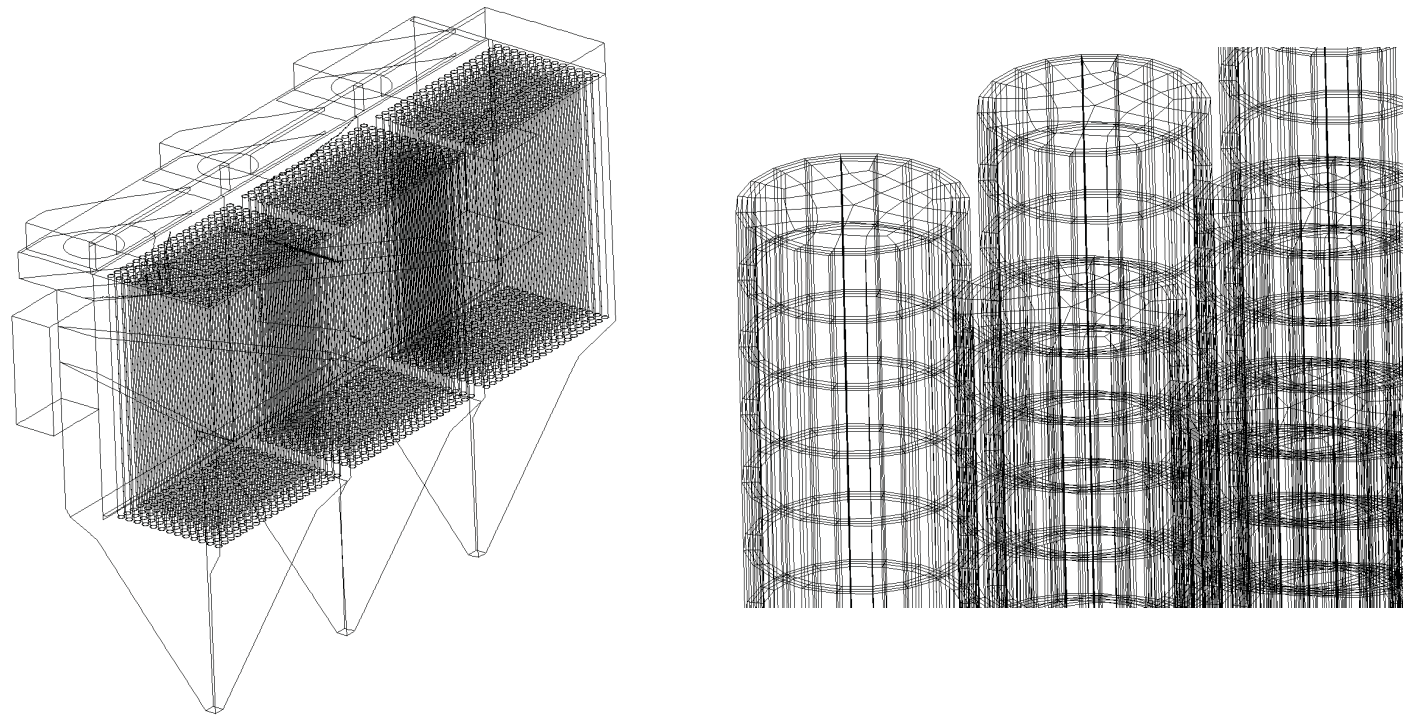

Figure 1: Geometry of the presented model and detail of filter bags mesh substitution of the bag wall by porous zone 
The porous media was modeled by the addition of a momentum source term to the standard fluid flow equations. The source term was composed of two parts: a viscous loss term (Darcy), and an inertial loss term. The equation (1) is valid for homogeneous porous media:

$$
S_{i}=-\left(\frac{\mu}{\alpha} \cdot v_{i}+C_{2} \cdot \frac{1}{2} \cdot \rho \cdot|v| \cdot v_{i}\right)
$$

where $\alpha$ is the permeability and $C_{2}$ is the inertial resistance factor [4].

The equation (1) corresponds to the equation often used to describe pressure drop of the filter bags. The first term is related to the filtering material (low velocity, laminar flow) and the second term is related to the dust layer.

The values of the permeability $\alpha$ and coefficient $C_{2}$ were defined on the base of known filtering material parameters and published data [1] [2] first. After, they have been stepwise modified with the aim to reach the experimental value of the filtering system pressure drop that was approx. $1000 \mathrm{~Pa}$.

The flow inside the filter was considered turbulent, standard $k-\varepsilon$ model and also RNG $k-\varepsilon$ model were employed. Uncompressible air with the density corresponding to the temperature $80^{\circ} \mathrm{C}$ was applied. The air velocity was defined 10 and $15 \mathrm{~m} / \mathrm{s}$ on the filter inlet. First, steady simulations were performed. Then also unsteady simulations were run in some cases. The second phase - dust particles were considered in the post processing or during the unsteady simulation. The simulations were done on PC cluster node with 8 processor cores and 64 GB RAM.

An example of computed results is presented in Figure 2. Left, there are presented contours of the static pressure; right, contours of the velocity magnitude. The inlet velocity was $15 \mathrm{~m} / \mathrm{s}$ in this case. It can be found that the pressure distribution is different in all three chambers. The filtering system pressure drop matches approximately the target value (pressure difference between the chamber with the filter bags and chamber over the bags outflows).
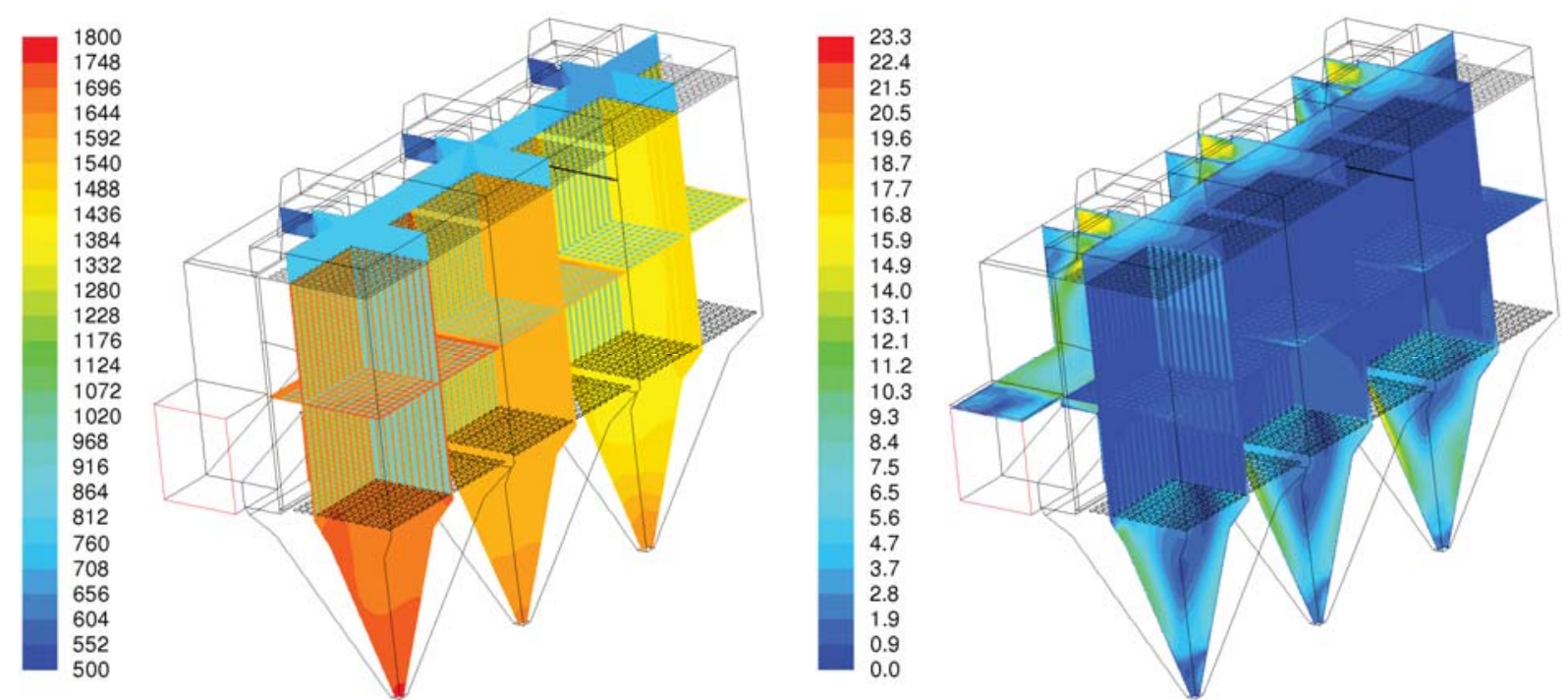

Figure 2:Examples of computed results - contours of the relative static pressure [Pa] and velocity $[\mathrm{m} / \mathrm{s}]$ on chosen model sections 
The velocities significantly exceed the value of $15 \mathrm{~m} / \mathrm{s}$ in the model, some streams with velocity over $10 \mathrm{~m} / \mathrm{s}$ occur also in the hopers. Streams with high velocity drifting heavy particles are the danger for the filter bags. The post processing was thereby focused also on analyses of streams and heavy particles trajectories in the filter bags neighborhood. The particles of different size were tracked and analyzed with respect to the location of their impact and their impact velocity.

Contours of the velocity magnitude in horizontal sections through one filter chamber can be found in the Figure 3. The sections start near the bags bottom, the last section is just bellow the bags suspension plate. Two main streams with higher velocities can be found in the corners of the chamber. The direction of the streams is luckily vertical without significant fluctuations. The particles are drifted up; the impact velocities on the filter bags walls are below $0.5 \mathrm{~m} / \mathrm{s}$. Also, very low velocities of the flow through the filtering material together with the velocity grow up inside the filter bags are well visible on the pictures.

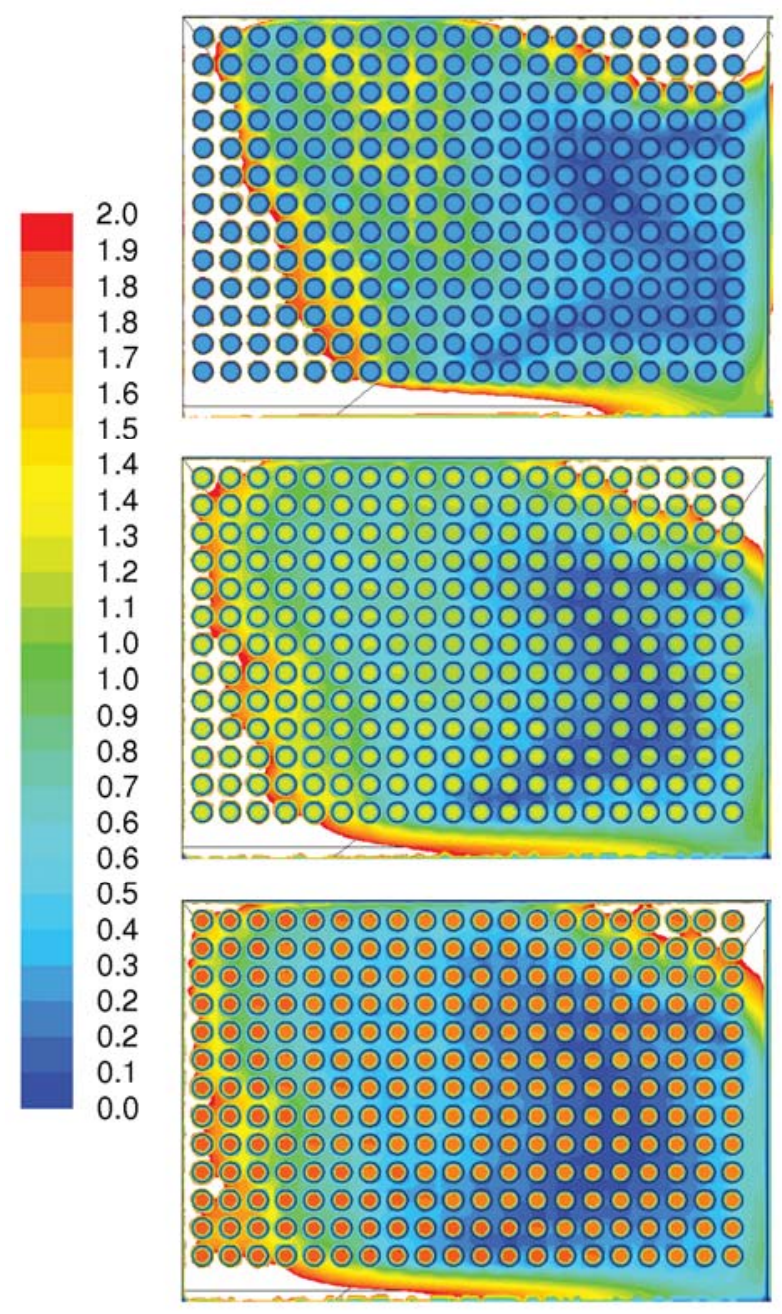

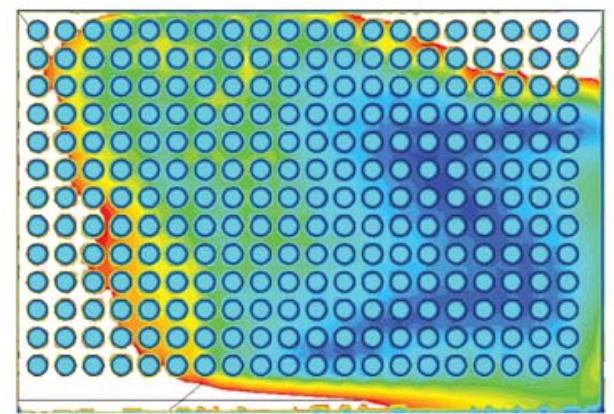
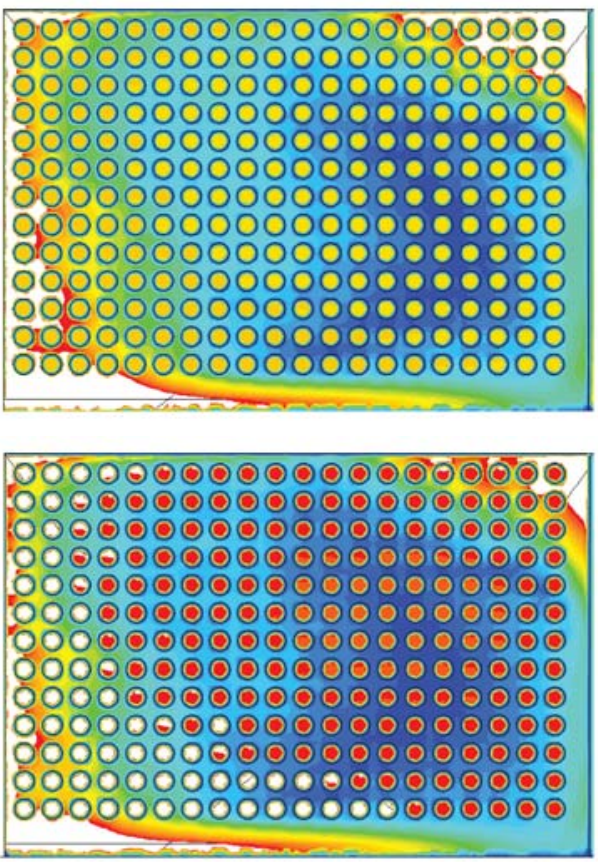

Figure 3: Contours of the velocity magnitude $[\mathrm{m} / \mathrm{s}]$ on horizontal sections through one filter chamber 


\section{CONCLUSIONS}

The performed simulations confirmed the possibility to analyze the filtering process in the fabric filters more in detail. On the other hand they shown also some difficulties related to the numerical simulations. Besides of the hardware and time requirements for the presented filtering material substitution, the main problem is specifying filtering material and dust layer characteristics. The filtering materials are often specified only by value of the pressure drop under standardized conditions, i.e. one value. The parameters of the dust layer are based on the experimental data and they can significantly differ for one material. Defining the values of the permeability $\alpha$ and coefficient $C_{2}$ and their mutual relation in the equation (1) thereby strongly depends on the user decision.

\section{ACKNOWLEDGEMENT}

The result was developed within the project PTSE, reg. no. 1 M06059 that is cofunded by the Ministry of Education, Youth and Sports of the Czech Republic.

\section{REFERENCES}

[1] Turner, J. H., McKenna, J. D., Mycock, J. C., Nunn, A. B., Vatavuk, W. M.: Fabric filters. Chapter 5. Research Triangle Institute 1998.

[2] Y.-H. Cheng and H.-J. Tsai, Factors influencing pressure drop through a dust cake during filtration. Aerosol Sci. Technol., 29 (1998), pp. 315-328.

[3] Richter, M.: Technologie ochrany životního prostředí - část II. Univerzita Jana Evangelisty Purkyně v Ústí nad Labem, Fakulta životního prostředí, 2002.

[4] ANSYS RELASE 13 Help - FLUENT. ANSYS Inc. 2010. 